\title{
Effect of maternal Helicobacter Pylori infection on birth weight in an urban community in Uganda
}

\author{
Ronald Wanyama ${ }^{1 *}$, Mike N. Kagawa ${ }^{2}$, Kenneth C. Opio $^{3}$ and Rhona K. Baingana ${ }^{4}$
}

\begin{abstract}
Background: Helicobacter pylori, a widespread infection particularly in developing countries has been associated with many adverse effects during pregnancy including hyperemesis gravidarum, neural tube defects in newborns, intrauterine fetal growth restriction and miscarriage. We sought to document the effects of $H$. pylori infection on birth weight in a low-income setting in Kampala, Uganda.

Methods: This was a prospective cohort study conducted in Kampala between May 2012 and May 2013. The participants were $H$. pylori positive and $H$. pylori negative HIV negative primigravidae and secundigravidae. Recruitment was at $\leq 18$ gestation weeks and follow up assessments were carried out at 26 and 36 gestation weeks and soon after delivery. H. pylori infection was determined using H. pylori stool antigen test. Maternal weight and height were measured, and body mass index (BMI) and gestational weight gain were calculated. Only term and live babies were considered. Low birth weight (LBW) was defined as a birth weight of <2500 gram.

Results: A total of 221 participants were enrolled with mean \pm standard deviation (SD) age of $20.9 \pm 2.7$ years. The mean \pm SD gestation age at delivery was $39.4 \pm 1.0$ weeks. Primigravidae were $61.5 \%(n=188)$ and $52.9 \%$ $(n=117)$ of the participants were positive for $H$. pylori infection. Low pre-pregnancy BMI $\left(<18.5 \mathrm{~kg} / \mathrm{m}^{2}\right)$ was recorded in $14.6 \%(n=28)$ while $38 \%(n=73)$ had a height $<156 \mathrm{~cm}$ at recruitment. Of the infants born to the participants, $13.6 \%(n=26)$ had low birth weight (<2500 gram).

Independent predictors for LBW were the mother being positive for $\mathrm{H}$. pylori infection (odds ratio, OR, 3.6, $95 \%$ $\mathrm{Cl} 1.1-11.5 ; P=0.031)$ maternal height at recruitment $<156 \mathrm{~cm}(\mathrm{OR} 3.4,95 \% \mathrm{Cl} 1.4-8.2 ; P=0.008)$ and maternal weight gain rates $<0.3 \mathrm{~kg} /$ week during the $2^{\text {nd }}$ and $3^{\text {rd }}$ trimesters (OR $3.8,95 \% \mathrm{Cl} 1.0-14.1 ; P=0.044$ ).
\end{abstract}

Conclusion: H. pylori infection is associated with LBW among primigravidae and secundigravidae in Kampala, Uganda.

Keywords: H. pylori infection, Pregnancy, Birth weight, Gestation weight gain, Kampala Uganda

\section{Background}

Helicobacter pylori (H. pylori) infection is the most common bacterial infection worldwide. Almost half of people in developed countries and three-quarters of people in developing countries are infected with $H$. pylori $[1,2]$. Although many infected individuals are asymptomatic, H. pylori is an important health problem. H. pylori infection has been recognized as a major cause of various gastroduodenal diseases, such as chronic gastritis, peptic

\footnotetext{
* Correspondence: rwanyama@gmail.com

${ }^{1}$ Department of Biochemistry, Faculty of Medicine, Gulu University, P.O. Box 166, Gulu, Uganda

Full list of author information is available at the end of the article
}

ulcer disease, and gastric cancer [3]. In Uganda the prevalence was $74 \%$ in patients with dyspepsia referred for endoscopy and $86 \%$ in patients with cancer and benign tumors $[4,5]$.

A high prevalence of $H$. pylori has been observed among pregnant women. In Uganda, Baingana et al. recently found $60 \%$ prevalence of $H$. pylori infection among pregnant women [6]. Studies in Sudan, Mexico and Chile found prevalence rate of $69.8 \%, 52.2 \%$ and $68.6 \%$ in respectively [7-9]. H. pylori infection in pregnancy is associated with many adverse effects, such as extreme, persistent nausea and vomiting (hyperemesis gravidarum) [8, 10], neural tube defects in newborns, pre-eclampsia with 
intrauterine fetal growth restriction and miscarriage, and thrombocytopenia [11-14]. Furthermore, pregnant women infected with $H$. pylori infection are at increased risk of anemia $[15,16]$.

Pregnancy is a physiological condition in which a marked increase in body weight occurs over a short period. An optimum weight gain over the course of pregnancy, as recommended by the Institute of Medicine (IOM, 2009), is one that produces a healthy newborn. Optimum weight gain also provides sufficient postpartum maternal fat stores to support lactation without increasing obesity risk [17]. Gestational weight gains below the IOM recommendation are common in developing countries [18]. There is evidence to show that maternal pre-pregnancy weight and the weight gained during pregnancy influence birth weight [19]. Inadequate gestational weight gain increases the risk of preterm delivery and low birth weight (LBW) infants [20, 21].

Birth weight is an important determinant of an infant's well-being. Infants born with LBW are at increased risk of morbidity and mortality from infectious disease, and suffer underweight, stunting or wasting beginning in the neonatal period through childhood [22]. There is evidence that adults born with LBW face an increased risk of chronic diseases including high blood pressure, type II diabetes mellitus, coronary heart disease and stroke in adulthood [23]. In Uganda, the prevalence of LBW, at $10.5 \%$, is high [24].

An association between $H$. pylori and LBW has been suggested [13, 14]. However, there is limited data on association between $H$. pylori and birth weight especially in developing countries. The objective of this study was to establish the association between $H$. pylori infection and birth weight.

\section{Methods}

\section{Study design and site}

This was a prospective cohort study in which pregnant women were followed from the time of recruitment up to delivery between May 2012 and May 2013. The study was conducted at the antenatal clinic of Kawempe Health Centre IV. The Health Centre is supported by the Ministry of Health, Uganda and the services in the antenatal clinic are free to the public. This clinic serves a denselypopulated, low-income area in Kawempe, one of the five Divisions forming Kampala District in Uganda. The Division is located in the Northern part of Kampala District.

\section{Study population}

Pregnant women attending antenatal at Kawempe Health Centre constituted the study population. The target population was HIV negative primigravidae and secundigravidae.

\section{Sample size}

We used online openEpi software, http://www.openepi-com, based on Kelsey Lesley (1996) to calculate sample size. In the formula we used a confidence level of $95 \%$, power of $80 \%$, ratio of $H$. pylori positive to $H$. pylori negative of one. Furthermore, in the formula we used 18 and 35 as the percentages of unexposed and exposed participants with outcome of interest according to Eslick [14]. The sample was divided two groups (exposed and unexposed). The exposed group (141) comprised of those who tested positive for $H$. pylori infection while the unexposed group (90) comprised who tested negative for $H$. pylori infection. We anticipated $5 \%$ lost to follow up.

\section{Recruitment and follow up}

A consecutive sampling procedure was used to select participants who met the selection criteria until the sample size was achieved. The participants were chosen as they got registered at the antenatal clinic. Written consent for each eligible participant was sought after clear information being given about the study objectives, procedures and benefits. In Uganda HIV testing for pregnant women is mandatory and is always done on the day of the first visit antenatal clinic. The study participants were recruited as informed volunteers at 12-18 weeks of gestation based on the reported last menstrual period and the experienced midwife's examination. Follow up assessments were carried at 26 and 36 weeks of gestation. This study only considered term neonates, that is, babies who were delivered after 37 weeks of gestation.

The study participants were included in our cohort based on the following criteria; between 18-35 years of age, pregnant for the first or second time, HIV negative, carrying singleton pregnancy, free of any systemic illness such as hypertension, active peptic ulcers, diabetes mellitus or genetic abnormality, for example, sickle cell disease, between gestation weeks $12-18$ at the time of recruitment. However, some of the pregnant women were excluded from this study based on the following criteria; not able to recall their pre-pregnancy weight, not able to schedule their return visits, not able to speak and/or hear, mentally ill, history of drug or alcohol abuse Based on the set exclusion criteria, a total of 56 women excluded from this study. Fourteen of them could not adhere to the scheduled return visits, 2 were sickle cell patients, 4 were alcohol abusers, 28 could not recall their pre-pregnancy weight, 6 had active peptic ulcers and 2 were carrying twins.

\section{Data collection and determination of nutritional status}

During participant's interview, demographic data including social, behavioral and medical history were collected in structured questionnaires. Nutritional status of each participant was assessed using anthropometric parameters. Anthropometric measurements were carried out in 
a closed room when the participant was barefoot and wearing light clothing. Body weight was measured using an adult a portable beam scale with $150 \mathrm{~kg}$ capacity divided into $0.5 \mathrm{~kg}$ increments (Gmbh \& co.kg, Germany model 7621019009). Height was determined with the individual barefoot and in an orthostatic position with the aid of a portable stadiometer consisting of a non-extendable 2 meter measuring tape divided into $0.1 \mathrm{~cm}$ increments. Body weight and height were measured twice for every participant and the average of the readings was considered as the participant's weight and height respectively. Each participant's BMI was calculated using the following formula: $\mathrm{BMI}=$ body weight $(\mathrm{kg})$ divided by [height $(\mathrm{m})]^{2}$. The BMI was categorized as follows; underweight $\left(<18.5 \mathrm{~kg} / \mathrm{m}^{2}\right)$, normal weight $\left(18.5-24.9 \mathrm{~kg} / \mathrm{m}^{2}\right)$, overweight $\left(25.0-29.9 \mathrm{~kg} / \mathrm{m}^{2}\right)$, obese $\left(\geq 30.0 \mathrm{~kg} / \mathrm{m}^{2}\right)$ [25]. The nutritional status of infants was assessed from the birth weight measurements. Birth weight was measured by baby weight scale (Fazzini) within $24 \mathrm{~h}$ after birth. A neonate was considered LBW if it weighed less than 2500 grams.

\section{Stool collection and testing for $\mathrm{H}$. Pylori infection}

After clear instructions on how to collect stool, each participant was given clean tissue paper on which to deposit the stool. After, she had to immediately transfer a stool sample into stool collection bottle using the scooper which was part of the bottle top. This was done in the antenatal clinic toilet. Stool samples were immediately placed in a cool box with ice packs. The samples were transported everyday from Kawempe Health Centre to the laboratory $(\sim 3 \mathrm{~km})$ and stored in a $-20^{\circ} \mathrm{C}$ freezer until analysis was carried out. H. pylori stool antigen test, i-Chek cassettes (Chem-Labs Limited, Nairobi, Kenya) were used to analyze the stool samples. It is a rapid one-step chromatographic immunoassay that utilizes a combination of anti-H. pylori antibodies and anti-mouse IgG. Instructions given by the manufacturer were followed. Approximately $100 \mu \mathrm{l}$ of stool of completely thawed stool was brought into the sample diluent tube and vortexed for fifteen seconds. Three drops of the diluted sample were applied to the test and the result was read after fifteen minutes. The results were reported as positive or negative on the basis of the manufacturer's guidelines. A procedural control was included with each test.

\section{Data analysis}

Data were analyzed using Statistical Package for Social Sciences (SPSS) V.16.0 (SPSS Inc., Chicago, IL, USA). Social, demographic and measurement parameters were summarized into frequencies and mean \pm standard deviation (SD). The outcome variable was birth weight while the predictor variables were $H$. pylori infection, rates of gestation weight gains pre-pregnancy weight, pre-pregnancy BMI, parity and maternal height. Continuous data were checked for normality. Tests for the significance of association were made using the Pearson chi-square $\left(\chi^{2}\right)$ test for categorical variables and independent sample $t$ test for continuous variables. Factors associated with birth weight were determined with logistic regression. Factors associated with birth weight with $P$ values $<0.05$ during univariate analysis were considered for multivariate analysis using logistic regression to determine factors independently associated with birth weight. Odds ratio (OR) and $95 \%$ confidence interval $(\mathrm{CI})$ were reported. At multivariate analysis, statistical significance was determined if $p<0.05$.

\section{Results}

Table 1 summarizes the overall socio-demographic characteristics of the study participants. Two hundred 221 HIV-negative pregnant women were enrolled into the study. 26 of the 221 were lost to follow up and of 26, 20 were negative for $H$. pylori infection. All the 221 enrolled were used to calculate the prevalence of $H$. pylori infection among the participants. The prevalence $H$. pylori infection was $52.9 \%(117 / 221)$. However, data from only 192 participants was used to perform all the other analyses because two of the participants lost their pregnancies at 22 and 25 weeks of gestation, one delivered before 37 weeks of gestation. Birth weight of one baby born to a participant who completed the study was not captured as it was still birth. $61.5 \%(188 / 192)$ of the participants were pregnant for the first time. $87.5 \%(168 /$ $192)$ of the participants were married, $9.9 \%(19 / 192)$ were single and the rest were either divorced/separated or widowed. Only $1.0 \%(2 / 192)$ and $5.2 \%(10 / 192)$ were smokers and were taking alcohol respectively. The majority, $64.6 \%(124 / 192)$, of the participants had acquired secondary education. The majority of the participants $78.1 \%$ $(144 / 192)$ were housewives and only $19.8 \%$ (38/192) were employed. Underweight $\left(\mathrm{BMI}<18.5 \mathrm{~kg} / \mathrm{m}^{2}\right)$ was recorded in $14.6 \%(28 / 192)$ of the participants. $38.0 \%(73 / 192)$ of the participants had height $<156 \mathrm{~cm}$ and $65.6 \%(126 / 192)$ were less than 21 years of age. Of the infants born to participants, $52.6 \%(101 / 192)$ were females and $13.6 \%$ (26/ $191)$ had low birth weight $(<2500 \mathrm{~g})$. From Tables 1 and 2 , we observe that there were no differences in the sociodemographic variables between the participants with $H$. Pylori infection and those without $H$. Pylori infection except for LBW $(P=0.002)$.

Table 3 shows the means \pm standard deviations (SD) and ranges for the selected variables and the difference between $H$. pylori positive and $H$. pylori negative participants. The participants had a mean $\pm \mathrm{SD}$ (kg/week) rate of weight gain of $0.30 \pm 0.11$ with a range of $0.08-0.75$ and there was a difference in the rates of weight gain between $H$. pylori positive and $H$. pylori negative participants $(P<0.001)$. The mean \pm SD gestation age at delivery was $39.4 \pm 1.0$ with a range of $37-42$ weeks. There was no difference in 
Table 1 Comparison of categorical socio-demographic characteristics by $H$. pylori status

\begin{tabular}{|c|c|c|c|}
\hline Variable $(n=192)$ & $\begin{array}{l}\text { H. pylori } \\
\text { positive }\end{array}$ & $\begin{array}{l}\text { H. pylori } \\
\text { negative }\end{array}$ & $P$ value \\
\hline \multicolumn{4}{|l|}{ Parity } \\
\hline Primigravidae & 70 & 48 & \\
\hline Secundigravidae & 40 & 34 & $0.473^{*}$ \\
\hline \multicolumn{4}{|l|}{ Marital status } \\
\hline Married & 94 & 74 & \\
\hline Single & 12 & 7 & \\
\hline Widowed/Divorced & 4 & 1 & $0.445^{*}$ \\
\hline \multicolumn{4}{|l|}{$\begin{array}{l}\text { Maternal pre-pregnancy } \\
\mathrm{BMI}\left(\mathrm{kg} / \mathrm{m}^{2}\right)\end{array}$} \\
\hline Underweight $(<18.5)$ & 15 & 13 & \\
\hline Normal weight (18.5-24.9) & 80 & 63 & \\
\hline Overweight (25.0-29.9) & 15 & 6 & $0.372^{*}$ \\
\hline \multicolumn{4}{|l|}{ Sex of the baby } \\
\hline Female & 56 & 44 & \\
\hline Male & 54 & 38 & 0.706 \\
\hline \multicolumn{4}{|l|}{ Birth weight (grams) ${ }^{a}$} \\
\hline$<2500$ & 22 & 4 & \\
\hline$\geq 2500$ & 87 & 78 & $0.002^{*}$ \\
\hline \multicolumn{4}{|l|}{$\begin{array}{l}\text { Maternal pre-pregnancy } \\
\text { height }(\mathrm{cm})\end{array}$} \\
\hline$<156$ & 42 & 31 & \\
\hline$\geq 156$ & 68 & 51 & $0.958^{*}$ \\
\hline \multicolumn{4}{|l|}{ Maternal age (years) } \\
\hline$<21$ & 70 & 56 & \\
\hline$\geq 21$ & 40 & 26 & $0.502^{*}$ \\
\hline Occupation & 79 & 65 & \\
\hline \multicolumn{4}{|l|}{ House wife } \\
\hline Peasant & 1 & 9 & \\
\hline Employee & 23 & 15 & \\
\hline Student & 7 & 2 & $0.561^{*}$ \\
\hline \multicolumn{4}{|l|}{ Smoking } \\
\hline Yes & 0 & 2 & \\
\hline No & 110 & 80 & $0.100^{*}$ \\
\hline \multicolumn{4}{|l|}{ Building type } \\
\hline Permanent & 108 & 82 & \\
\hline Temporary & 2 & 0 & $0.518^{*}$ \\
\hline \multicolumn{4}{|l|}{ Alcohol } \\
\hline Yes & 5 & 5 & \\
\hline No & 105 & 77 & $0.632^{*}$ \\
\hline \multicolumn{4}{|l|}{ Water source } \\
\hline Tap & 87 & 64 & \\
\hline Borehole & 6 & 5 & \\
\hline Protected well & 17 & 11 & \\
\hline
\end{tabular}

Table 1 Comparison of categorical socio-demographic characteristics by H. pylori status (Continued)

\begin{tabular}{|c|c|c|c|}
\hline Unprotected well & 0 & 1 & \\
\hline Tank (harvested rain water) & 0 & 1 & $0.490^{*}$ \\
\hline \multicolumn{4}{|l|}{ Education level } \\
\hline $\begin{array}{l}\text { Low (No education } \\
\text { to primary } 7 \text { ) }\end{array}$ & 22 & 20 & \\
\hline Medium (Secondary level) & 72 & 52 & \\
\hline High (tertiary education) & 16 & 10 & $0.114^{*}$ \\
\hline \multicolumn{4}{|l|}{$\begin{array}{l}\text { Household monthly } \\
\text { income (\$) }\end{array}$} \\
\hline Low income $(<100)$ & 56 & 38 & \\
\hline Medium income (101-250) & 46 & 41 & \\
\hline High income (>250) & 8 & 3 & $0.374^{*}$ \\
\hline
\end{tabular}

mean gestation age at delivery between $H$. pylori positive and $H$. pylori negative participants $(P=0.494)$. The mean \pm SD birth weight was $2922 \pm 476 \mathrm{~g}$ with a range of 1700 $4400 \mathrm{~g}$ and the mean birth weight of babies born to $\mathrm{H}$. pylori positive mothers was significantly different from that of babies born to $H$. pylori negative participants $(P<$ 0.001 ). The mean \pm SD (range) pre-pregnancy weight, pre-pregnancy BMI and maternal height were $53.1 \pm$ $7.7 \mathrm{~kg}(37-76 \mathrm{~kg}), 21.5 \pm 2.7 \mathrm{~kg} / \mathrm{m}^{2}\left(15.0-29.4 \mathrm{~kg} / \mathrm{m}^{2}\right)$ and $157.4 \pm 5.8 \mathrm{~cm}(142.0-173.1 \mathrm{~cm})$ respectively. The mean pre-pregnancy weight, pre-pregnancy BMI and maternal height of $H$. pylori positive participants were not significantly different from those of $H$. pylori negative participants.

\section{Factors associated with low birth weight}

For logistic regression, low birth weight (BW $<2500$ grams) was used as the outcome variable. The covariates were $H$. pylori status, maternal gestation rate of weight gain, maternal height, and parity (Table 4). However, the independent predictors for LBW were the mother being positive for H. pylori infection (odds ratio, OR, 3.6, $95 \%$ CI 1.1$11.5 ; P=0.031$ ), maternal height at recruitment $<156 \mathrm{~cm}$ (OR 3.4, $95 \%$ CI 1.4-8.2; $P=0.008$ ) and maternal

Table 2 Comparison of continuous socio-demographic characteristics by H. pylori status

\begin{tabular}{lccc}
\hline Variable $(n=192)$ & $\begin{array}{c}\text { H. pylori } \\
\text { positive }\end{array}$ & $\begin{array}{l}\text { H. pylori } \\
\text { negative }\end{array}$ & $P$ value \\
\hline Maternal age (years) & 21.1 & 20.8 & $0.481^{* *}$ \\
Mean household size & 3.0 & 2.8 & $0.462^{* *}$ \\
Mean maternal recruitment & 21.6 & 21.2 & $0.352^{* *}$ \\
BMl $\left(\mathrm{kg} / \mathrm{m}^{2}\right)$ & & & \\
Mean maternal height $(\mathrm{cm})$ & 157.5 & 157.2 & $0.727^{* *}$ \\
\hline
\end{tabular}

${ }^{* *} P$ valve for the independent sample $t$ test and $n$ is number 
Table 3 Mean \pm SD values selected variables in relation to $H$. pylori infection status

\begin{tabular}{|c|c|c|c|c|}
\hline \multirow[t]{2}{*}{ Variable } & \multicolumn{2}{|c|}{ Mean \pm SD by H. Pylori Status } & \multirow[t]{2}{*}{ Range } & \multirow[t]{2}{*}{$P$ valve } \\
\hline & H. pylori -ve $(n=82)$ & H. pylori + ve $(n=110)$ & & \\
\hline Rate of weight gain (kg/week) & $0.33 \pm 0.11$ & $0.26 \pm 0.10$ & $0.08-0.75$ & $<0.001$ \\
\hline Gestational age (weeks) & $39.4 \pm 1.1$ & $39.3 \pm 1.0$ & $37.0-42.0$ & 0.494 \\
\hline Birth weight (g) & $3245 \pm 407$ & $2681 \pm 370$ & $1700-4400$ & $<0.001$ \\
\hline Pre-pregnancy BMI (kg/m²) & $21.2 \pm 2.5$ & $21.6 \pm 2.9$ & $15.0-29.4$ & 0.35 \\
\hline Pre-pregnancy weight (kg) & $52.6 \pm 7.0$ & $53.5 \pm 8.1$ & $37-76$ & 0.392 \\
\hline Maternal height $(\mathrm{cm})$ & $157.3 \pm 5.9$ & $157.5 \pm 5.9$ & $142.0-173.1$ & 0.727 \\
\hline
\end{tabular}

gestation weight gain rates $<0.3 \mathrm{~kg} /$ week during the $2^{\text {nd }}$ and $3^{\text {rd }}$ trimesters (OR 3.8, $95 \%$ CI 1.0-14.1; $P=0.044$ ) (Table 5).

\section{Discussion}

The prevalence of $H$. pylori infection on the basis of presence of $H$. pylori stool antigens in this population of primigravidae and secundigravidae was $52.9 \%$. This is within the range expected considering our country's socioeconomic level and prevalence of the infection among pregnant women attending antenatal care clinic in the same health centre in Kampala [2, 6]. The high rate of $H$. pylori infection in this study mirrors the observation of $69.8 \%, 68.5 \%$ and $52.2 \%$ rate of $H$. pylori infection among pregnant women in neighboring Sudan, Chile and rural Mexico respectively [7-9]. Higher prevalence, $74 \%$ and $88 \%$, of $H$. pylori infection was reported among pregnant women at the US-Mexico border and Egypt respectively [26, 27]. Our study comprised on primigravidae and secundigravidae with the a mean \pm SD age of $20.9 \pm 2.7$ years and there is evidence that prevalence of $H$. pylori infection increase with increasing age and number of deliveries [9].

Infants born from $H$. pylori positive women had a significantly lower mean \pm SD birth weight $(2681 \pm 370 \mathrm{~g})$ than those born from $H$. pylori negative women (3245 \pm 407 g) $P<0.001$. This perfectly agrees with the findings of the study done in Turkey by Mulayim et al. [16]. Similarly infants born to primigravidae had a significantly lower mean \pm SD birth weight $(2791 \pm 422 \mathrm{~g})$ than those born to secundigravidae $(3210 \pm 465$ g) $P<0.001$. This finding is in agreement with the findings of Chiba et

Table 4 Factor associated with low birth weight at univariate analysis

\begin{tabular}{lcl}
\hline Variable & $\begin{array}{c}\text { Odds ratio } \\
\text { for LBW }\end{array}$ & $\begin{array}{l}P \text { valve } \\
(95 \% \mathrm{Cl})\end{array}$ \\
\hline Maternal rate of weight gain $<0.3 \mathrm{~kg} /$ week & 5.1 & $0.011(1.5,17.5)$ \\
Maternal height $<156 \mathrm{~cm}$ & 3.0 & $0.012(1.3,6.8)$ \\
Primigravidae & 1.4 & $0.048(1.1,3.4)$ \\
H. pylori infection & 4.9 & $0.005(1.6,14.8)$ \\
\hline
\end{tabular}

al. [28]. However, there were no differences in the LBW prevalence between infants born to primigravidae and those born to secundigravidae $(P=0.70)$. This finding is in contrast with the findings of Chiba and his colleagues who found out that the LBW rate was significantly higher in primigravidae than in multigravidae females. This difference could be because our study population was homogenous in most of the socio-demographic and nutritional characteristics to detect significant association.

The prevalence of LBW in this study population was $13.6 \%$ and this was slightly higher than the National LBW prevalence $(10.5 \%)$ but mirrors the $14 \%$ which has been reported in parts of central Uganda where this study was conducted [24]. We believe LBW in this urban population was higher because of the nature of the population we studied. In the present study, only those women pregnant for the $1^{\text {st }}$ or $2^{\text {nd }}$ time with mean $\pm S D$ age was $20.9 \pm$ 2.7 years were included while women of urban and rural communities irrespective of gravidae and age were studied in the National survey [24]. A good number of our participants $(38.5 \%)$ were pregnant for the $2^{\text {nd }}$ time with mean \pm SD age of $21.7 \pm 3.2$ years. There is a body of evidence which show that first born and second born babies born to adolescents have higher chances of being born LBW [29]. There is also current evidence that age $<20$ years increases the risk of giving birth to LBW baby [30].

In this study we found $H$. pylori infection to be an independent predictor of low birth weight $(\mathrm{OR}=3.6,95 \% \mathrm{CI}$ : $1.1-11.5 ; P=0.031)$. Our finding is in agreement with the finding of Eslick et al. and Mulayim et al. [14, 16]. Eslick et al. (2002) observed for the first time association between H. pylori infection and low birth weight, in particular they

Table 5 Factor independently associated with low birth weight

\begin{tabular}{lcl}
\hline Variable & $\begin{array}{c}\text { Odds ratio } \\
\text { for LBW }\end{array}$ & $\begin{array}{l}P \text { valve } \\
(95 \% \mathrm{Cl})\end{array}$ \\
\hline H. pylori infection & 3.6 & $0.031(1.1,11.5)$ \\
Maternal rate of weight gain $<0.3 \mathrm{~kg} /$ week & 3.8 & $0.044(1.0,14.1)$ \\
Maternal height $<156 \mathrm{~cm}$ & 3.4 & $0.008(1.4,8.2)$ \\
Primigravidae & 1.08 & $0.895(0.34,3.4)$ \\
\hline $\begin{array}{l}\text { Variables entered on step 1: H. pylori infection, maternal rate of weight gain, } \\
\text { maternal height, and parity }\end{array}$
\end{tabular}


showed that intrauterine growth restriction was more common in $H$. pylori positive women $(13.5 \%)$ than in negative mothers $(6.0 \%)(\mathrm{OR}=2.41 ; 95 \% \mathrm{CI}: 1.14-5.08$; $P=0.018$ ). Mulayim et al. observed that pregnant women with $H$. pylori infection delivered neonates with a significantly lower birth-weight compared to mothers without the infection. Furthermore, in animal models, it has been reported that $H$. pylori infected mice showed a decrease in implantation rates, and their offspring were of low birth weight [31]. However, in another experimental mice model study these results were not confirmed [32]. The mechanism(s) by which $H$. pylori infection causes fetal growth retardation is/are not very clear but several have been suggested. $H$. pylori has been linked with an increase in symptoms including dyspepsia, nausea or vomiting [8], because of underlying undiagnosed peptic ulcer disease, which in turn may affect maternal gastric absorption and therefore impair fetal growth. In humans, $H$. pylori infection has also been associated with anemia [33] and maternal anemia associated to $H$. pylori infection may lead to fetal growth restriction. In the study by Jasem et al., [33], fetal growth retardation could have been due to maternal anemia since all anemic pregnant women were in the $H$. pylori positive group. Fetal growth retardation may be due to either maternal or feto-placental causes. Feto-placental causes include infections and other placental pathologies [34]. It has been demonstrated that anti-CagA antibodies cross-react in vitro with placental tissue reducing its invasiveness ability [35] and the consequent abnormal placentation could lead to fetal growth restriction [34]. However, Cardaropoli et al. found a strong association between $H$. pylori infection and fetal growth retardation in preeclamptic pregnancies, while there was no association between $H$. pylori and idiopathic fetal growth retardation [12].

The pattern of maternal weight gain during pregnancy is an important determinant of fetal growth [17]. This study found out that primigravidae had a higher mean \pm SD rate of weight gain $(0.33 \pm 0.11 \mathrm{~kg} /$ week $)$ than secundigravidae $(0.27 \pm 0.10 \mathrm{~kg} /$ week $) P<0.001$. This finding is in agreement with recent findings of Lumbanrajaa et al., [36]. This present study also found rates of gestation weight gain rates $<0.30 \mathrm{~kg} /$ week during the $2^{\text {nd }}$ and $3^{\text {rd }}$ trimesters to be an independent predictor of low birth weight $(\mathrm{OR}=3.8,95 \% \mathrm{CI} 1.0-14.1 ; P=0.044)$. This finding of ours agrees with several other studies which have reported that birth weight has positive correlations with maternal gestation weight [37-39].

There was no difference in mean \pm SD maternal height between $H$. pylori positive $(157.54 \pm 5.92 \mathrm{~cm})$ and $H$. pylori negative $(157.25 \pm 5.92 \mathrm{~cm})(P=0.73)$. However, maternal height less than $156 \mathrm{~cm}$ was another important parameter which independently increased the risk for LBW (OR $=3.4,95 \%$ CI 1.4-8.2; $P=0.008)$. Our cut off point of $156 \mathrm{~cm}$ agrees well with other investigators in
Sudan, Brazil and Bangladesh who also found that maternal height below $156 \mathrm{~cm}$ increases the risk for LBW and child mortality [30, 40, 41]. Elshibly et al. [41] found maternal height $<156 \mathrm{~cm}$ to increase LBW (AUC 0.591, $95 \%$ CI $0.560-0.622 ; P=0.003$ ). This confirms the value of maternal height as a predictor of childhood morbidity and mortality.

The strength of our study lies in the fact it was a prospective cohort and we were able to control some of the known risk factors for LBW such as preterm delivery, chronic and genetic diseases. We also included a homogenous population and we are able to attribute the birth weights to $H$. pylori infection. We also included only children delivered after 37 weeks of gestation so premature babies were not part of our cohort. However, this current study had some limitations. We did not collect data of all the risk factors for LBW, for example, anemia, level of physical activity during pregnancy, number of antenatal visits, previous poor pregnancy outcome for secundigravidae and complications which occurred during pregnancy and labor neither did we consider other infections, such as malaria and helmith, which are endemic in the area and were previously reported as a cause of low LBW $[42,43]$.

\section{Conclusion}

In conclusion, the most important finding of this study was that $H$. pylori infected pregnant women showed a significantly a higher risk of giving birth to LBW babies. In addition, primigravidae and secundigravidae with less a height less than $156 \mathrm{~cm}$ had a higher risk of giving birth to LBW babies. Irrespective of Maternal $H$. pylori infection status, maternal height and gestation rates of weight gain remained the most important factors for LBW.

\section{Recommendations}

We recommend $H$. pylori infection screening for women of child bearing age. Those found positive for H. pylori infection should be treated before they get pregnant since the available drug regimes for treatment of $\mathrm{H}$. pylori are not safe in pregnancy. Pregnant women should also be routinely counseled and monitored for gestation weight gain to ensure adequate weight which results into a normal birth weight baby.

\section{Abbreviations}

BMI, body mass index; H. pylori, Helicobacter pylori; HIV, Human immunodeficiency virus; IOM, Institute of Medicine; LBW, low birth weight; OR, odds ratio; SD, standard deviation; SPSS, statistical package for social Scientists; WHO, World Health Organization

\section{Acknowledgments}

We are thankful to the women who participated in this study. The authors would like to thank the administration and staff of Kawempe Health Centre antenatal clinic. The authors are grateful to ENRECA-Gulu University project for facilitating the data collection process. The content is solely our responsibility as authors and does not necessarily represent the official views of the IAEA. 


\section{Funding}

This study was supported by the International Atomic Energy Agency (IAEA).

\section{Availability of data and materials}

Raw data and data collection tools can be available on request by writing to the corresponding author whose e-mail is rwanyama@gmail.com.

\section{Authors' contributions}

RW conceived the idea and developed the study concept. Oversaw the process of data collection and entry, designed the analysis plan, interpreted the data, and drafted the manuscript. MK and KCO were involved in the development and writing of the study proposal and provided critical revision of the manuscript for intellectual content. RKB provided laboratory assistance and critical revision of the manuscript for intellectual content. All authors read and approved the final manuscript.

\section{Competing interests}

The authors declare that they have no competing interests.

\section{Consent for publication}

This is not applicable.

\section{Ethics approval and consent to participate}

The study protocol was reviewed and approved by the Research and Ethics Committee of the School of Medicine Makerere University (REC REF No. 2011-007). The study was cleared by the Uganda National Council of Science and Technology (HS 921). Permission to conduct the study at Kawempe Health Centre IV was granted by the Kampala Capital City Authority Health Department. Each participant received standard information about the nature of the study and the procedures involved. Participation in the study was voluntary and each participant signed a consent form.

\section{Author details}

'Department of Biochemistry, Faculty of Medicine, Gulu University, P.O. Box 166, Gulu, Uganda. ${ }^{2}$ Department of Obstetrics \& Gynecology, College of Health Sciences, Makerere University, P.O. Box 7062, Kampala, Uganda. ${ }^{3}$ Department of Internal Medicine, College of Health Sciences, Makerere University, P.O. Box 7062, Kampala, Uganda. ${ }^{4}$ Department of Biochemistry and Sports Science, School of Biological Sciences, Makerere University, P.O. Box 7062, Kampala, Uganda.

Received: 3 July 2015 Accepted: 9 July 2016

Published online: 13 July 2016

\section{References}

1. Ford AC, Axon AT. Epidemiology of Helicobacter pylori infection and public health implications. Helicobacter. 2010;15 Suppl 1:1-6.

2. Hunt RH, Xiao SD, Megraud F, Leon-Barua R, Bazzoli F,van der Merwe S et al. Helicobacter pylori in developing countries. World Gastroenterology Organisation Global Guidelines August 2010

3. Dial EJ, Lichtenberger LM. Effect of lactoferrin on Helicobacter felis induced gastritis. Biochem Cell Biol. 2002;80:113-7.

4. Ochama P. Testing for Helicobacter pylori status in patients undergoing diagnostic endoscopy in Mulago and Nsambya Hospitals, Dissertation. Kampala: Makerere University; 2001.

5. Newton R, Ziegler JL, Casabonne D, Carpenter L, Gold BD, Owens M, Beral V, Mbidde E, Parkin DM, Wabinga H, Mbulaiteye S, Jaffe H. Helicobacter pylori and cancer among adults in Uganda. Infect Agent Cancer. 2006;1:5.

6. Baingana RK, Enyaru JK, Davidsson L. Helicobacter pylori infection in pregnant women in four districts of Uganda: role of geographic location, education and water sources. BMC Public Health. 2014;14:915.

7. Mubaraka N, Gasimb Gl, Khalafallac KE, Alid NI, Adama I. Helicobacter pylori, anemia, iron deficiency and thrombocytopenia among pregnant women at Khartoum, Sudan. Trans R Soc Trop Med Hyg. 2014.

8. Poveda GF, Carrillo KS, Monje ME, Cruz CA, Cancino AG. Helicobacter pylori infection and gastrointestinal symptoms on Chilean pregnant. Rev Assoc Med Bras. 2014;60(4):306-10.

9. Alvarado-Esquivel C. Seroepidemiology of Helicobacter pylori infection in pregnant women in rural Durango, Mexico. Int J Biomed Sci. 2013;9(4):224-9.
10. Nanbakhsh F, Mohaddesi H, Bahadory F, Amirfakhrian J, Mazloomi P. Comparison of helicobacter pylori infection between pregnant women with hyperemesis gravidarum and controls. World Appl Sci J. 2013;28(12):1918-22.

11. Golalipour MJ, Sedehi M, Qorbani M. Does maternal Helicobacter pylori infection increase the risk of occurrence of neural tube defects in newborns in Northern Iran? Neurosciences (Riyadh). 2012;17:219-25.

12. Cardaropoli S, Rolfo A, Piazzese A, et al. Helicobacter pylori's virulence and infection persistence define pre-eclampsia complicated by fetal growth retardation. World J Gastroenterol. 2011;17:5156-65.

13. Hajishafiha M, Ghasemi-Rad M, Memari A, et al. Effect of Helicobacter pylori infection on pregnancy rates and early pregnancy loss after intracytoplasmic sperm injection. Int J Womens Health. 2011;3:329-35.

14. Eslick GD, Yan P, Xia HH, Murray H, Spurrett B, Talley NJ. Foetal intrauterine growth restrictions with Helicobacter pylori infection. Aliment Pharmacol Ther. 2002;16:1677-82

15. Farag TH, Stoltzfus RJ, Khalfan SS, Tielsch JM. Helicobacter pylori infection is associated with severe anemia of pregnancy on Pemba Island, Zanzibar. Am J Trop Med Hyg. 2007;76:541-8.

16. Mulayim B, Celik NY, Yanik FF. Helicobacter pylori infection detected by 14 Curea breath test is associated with iron deficiency anemia in pregnant women. J Obstet Gynaecol Res. 2008;34:980-5.

17. Institute of Medicine. Weight gain during pregnancy: re-examing the guidelines. Washington, DC: The National Academies Press; 2009. p. 233.

18. Maddah M, Karandish M, Mohammadpour-Ahranjani B, et al. Social factors and pregnancy weight gain in relation to infant birth weight: a study in public health centers in Rasht, Iran. Eur J Clin Nutr. 2005;59:208-1212.

19. Forsum E, Lof M, Olausson H, Olhager E. Maternal body composition in relation to infant birth weight and subcutaneous adipose tissue. $\mathrm{Br} J$ Nutr. 2006;96:408-14.

20. Dietz P, Callaghan W, Cogswell M, Morrow B, Ferre C, Schieve L. Combined effects of prepregnancy body mass index and weight gain during pregnancy on the risk of preterm delivery. Epidemiology. 2006;17:170-7.

21. Stotland NE, Cheng YW, Hopkins LM, Caughey AB. Gestational weight gain and adverse neonatal outcome among term infants. Obstetr Gynecol. 2006;108:635-43.

22. Jarvis S, Glinianaia SV, Torrioli MG, Platt MJ, Miceli M, et al. Cerebral palsy and intrauterine growth in single births: European collaborative study. Lancet. 2003:362:1106-11.

23. Barker DJ. The developmental origins of adult disease. J Am College Nutr. 2004;23:5885-95.

24. Uganda Bureau of Statistics (UBOS) and ICF International Inc. Uganda demographic and health survey 2011. Kampala: UBOS and Calverton, Maryland: ICF International Inc; 2012.

25. World Health Organization. Physical status: the use and interpretation of anthropometry. Geneva: Report of a WHO Expert Committee; 1995.

26. Goodman KJ, O'Rourke K, Day RS, et al. Helicobacter pylori infection in pregnant women from a US-Mexico border population. J Immigr Health. 2003;5:99-107.

27. Mansour GM, Nashaat EH. Role of Helicobacter pylori in the pathogenesis of hyperemesis gravidarum. Arch Gynecol Obstet. 2011;284:843-7.

28. Chiba T, Ebina S, Kashiwakura I. Influence of maternal body mass index on gestational weight gain and birth weight: A comparison of parity. Exp Therapeutic Med. 2013;6:293-8.

29. Partington SN, Steber DL, Blair KA, Cisler RA. Second births to teenage mothers: risk factors for low birth weight and preterm birth. Perspect Sex Reprod Health. 2009;41:101-9.

30. Britto RPA, Florêncio TMT, Benedito Silva AA, Sesso R, Cavalcante JC, et al. Influence of maternal height and weight on low birth weight: a cross-sectional study in poor communities of northeastern Brazil. PLoS One. 2013;8(11):e80159.

31. Rossi G, Romagnoli S, Lauretti L, Pancotto L, Taccini E, Rappuoli R, Del Giudice G, Ruggiero P. Helicobacter pylori infection negatively influences pregnancy outcome in a mouse model. Helicobacter. 2004;9:152-7.

32. Gøbel R, Symonds EL, Butler RN, Tran CD. Association between Helicobacter pylori infection in mothers and birth weight. Dig Dis Sci. 2007;52:3049-53.

33. Jasem MA, Al-Ubaidi AA, Daood NM, Muhsin JA. Iron deficiency in Helicobacter pylori infected patients in Baghdad. J Microbiol Infect Dis. 2011;1(3):114-7

34. Cardaropoli S, Rolfo A, Todros T. Helicobacter pylori and pregnancy-related disorders. World J Gastroenterol. 2014;20(3):654-64.

35. Franceschi F, Di Simone N, D'Ippolito S, Castellani R, Di Nicuolo F, Gasbarrini G, Yamaoka Y, Todros T, Scambia G, Gasbarrini A. Antibodies anti-CagA 
cross-react with trophoblast cells: a risk factor for pre-eclampsia? Helicobacter. 2012;17:426-34.

36. Lumbanrajaa S, Lutana D, Usmana I. Maternal weight gain and correlation with birth weight infants. Procedia Soc Behav Sci. 2013;103:647-56.

37. Terada M, Matsuda Y, Ogawa M, Matsui H, Satoh S. Effects of maternal factors on birth weight in Japan. J Pregnancy. 2013;Article ID 172395:5.

38. Chihara I, Hayes DK, Chock LR, Fuddy LJ, Rosenberg DL, Handler AS. Relationship between gestational weight gain and birth weight among clients enrolled in the Special Supplemental Nutrition Program for Women, Infants, and Children (WIC), Hawaii, 2003-2005. Matern Child Health J. 2014:18(5):1123-31.

39. Shrestha I, Sunuwar L, Bhandary S, Sharma P. Correlation between gestational weight gain and birth weight of the infants. Nepal Med Coll J. 2010;12(2):106-9.

40. Elshibly EM, Schmalisch G. The effect of maternal anthropometric characteristics and social factors on gestational age and birth weight in Sudanese newborn infants. BMC Public Health. 2008;8:244.

41. Baqui AH, Arifeen SE, Amin S, Black RE. Levels and correlates of maternal nutritional status in urban Bangladesh. Eur J Clin Nutr. 1994;48:349-57.

42. Woodburn PW, Muhangi L, Hillier S, Ndibazza J, Namujju PB, et al. Risk factors for helminth, malaria, and HIV infection in pregnancy in Entebbe, Uganda. PLoS Negl Trop Dis. 2009;3(6):e473.

43. De Beaudrap P, Turyakira E, White L, Nabasumba C, Tumwebaze B, et al. Impact of malaria during pregnancy on pregnancy outcomes in a Ugandan prospective cohort with intensive malaria screening and prompt treatment. Malar J. 2013;12:139.

\section{Submit your next manuscript to BioMed Central and we will help you at every step:}

- We accept pre-submission inquiries

- Our selector tool helps you to find the most relevant journal

- We provide round the clock customer support

- Convenient online submission

- Thorough peer review

- Inclusion in PubMed and all major indexing services

- Maximum visibility for your research

Submit your manuscript at www.biomedcentral.com/submit

C Biomed Central 